\title{
Relationship changes in lifestyle, cardiovascular risk factors, and mental health in Japanese workers: A four-year follow up with high-risk and population strategies of the occupational health promotion (HIPOP-OHP) study
}

\author{
Junko Minai ${ }^{1,2^{*}}$, Taichiro Tanaka ${ }^{2,3}$, Tomonori Okamura ${ }^{4}$, Shunichi Fukuhara ${ }^{5}$, \\ Yoshimi Suzukamo ${ }^{6}$, Hirotsugu Ueshima ${ }^{7}$, Zentaro Yamagata ${ }^{2}$ \\ ${ }^{1}$ School of Nursing and Rehabilitation Science, Odawara International University of Health and Welfare, Odawara, Japan; \\ *Corresponding Author: jminai@iuhw.ac.jp \\ ${ }^{2}$ Department of Health Sciences, School of Medicine, University of Yamanashi, Chuo, Japan \\ ${ }^{3}$ Department of Environmental and Occupational Health, Faculty of Medicine, Toho University, Tokyo, Japan \\ ${ }^{4}$ Department of Preventive Medicine and Public Health, Keio University, Tokyo, Japan \\ ${ }^{5}$ Department of Healthcare Epidemiology, Kyoto University Graduate School of Medicine and Public Health, Kyoto, Japan \\ ${ }^{6}$ Department of Physical Medicine and Rehabilitation, Tohoku University Graduate School of Medicine, Sendai, Japan \\ ${ }^{7}$ Department of Health Science, Shiga University of Medical Science, Otsu, Japan
}

Received 24 August 2012; revised 26 September 2012; accepted 13 October 2012

\section{ABSTRACT}

Background: Cardiovascular diseases (CVD) are major causes of death in Japan, and controlling the risk factors for CVD is an important public health task. Lifestyle factors, for example, diet and stress, have impacts on risk factors such as hypertension and hyperlipidemia. Deterioration of mental health is related to CVD pathogenesis. Aim: We investigated the relationships between levels of mental health, 4-year changes in lifestyle, and CVD risk factors among Japanese workers, using the SF-36 (Japanese version), which is a comprehensive scale measuring health-related quality of life. We hypothesized that workers' mental health levels would influence 4-year changes in their lifestyles and CVD risk factors. Methods: Data from the High-Risk and Population Strategy for Occupational Health Promotion (HIPOP-OHP) study, which were collected by examination and administration of the SF-36, were used. The relationships between mental health levels at baseline, lifestyle changes, and cardiovascular risk factors were longitudinally analyzed. Subjects with total SF-36 scores $\geq 65$ were classified as the "Good Mental Health Group," and those with total scores $<65$ were classified as the "Poor Mental Health Group." Results: Multiple logistic regression analyses showed that, as compared to people who had poor mental health, those who had good mental health at baseline had a significantly higher probability of good maintenance of improvements in body mass index, $(O R=1.20$, $95 \% \mathrm{Cl}: 1.03-1.39)$, blood pressure (OR $=1.20$, $95 \% \mathrm{Cl}: 1.01-1.43)$, total cholesterol (OR $=1.07$, $95 \% \mathrm{Cl}: 0.86-1.33)$ and $\mathrm{HDL}$ cholesterol $(\mathrm{OR}=$ 1.26, 95\% Cl: 1.07 - 1.47). Conclusion: Japanese workers with good mental health tend to improve or maintain good lifestyle conditions and minimize CVD risk factors, while those with poor mental health generally have difficulty improving their lifestyles and lowering their CVD risk.

Keywords: Lifestyle; Cardiovascular Risk Factors; Mental Health; Japanese Workers; HIPOP-OHP

\section{INTRODUCTION}

Cardiovascular diseases (CVD), including cerebrovascular diseases and coronary artery disease, are major causes of death in Japan [1,2], and controlling the risk factors for CVD is an important task for public health. Lifestyle, including diet, exercise, smoking, and alcohol consumption, is related to the formation of risk factors for diseases such as hypertension and hyperlipidemia, which are relevant to the pathogenesis of CVD. Therefore, improvements in lifestyle are important in preventing CVD [3-8]. Furthermore, a relationship between the 
pathogenesis of CVD and stress has been reported [912].

Recently, in Japan, the environment for workers has significantly changed because of stagnated economic growth, the increasing mobility of the workforce, highly networked information, globalization, etc. Such changes result in an increasing number of workers who suffer from stress and mental health problems, and deterioration of mental health has become a significant social problem $[13,14]$. There are various reports on the relationship between mental health and the pathogenesis of CVD in Europe and the United States [15,16]. However, in Japan, very few prospective studies have investigated how mental health affects the pathogenesis and risk factors of CVD or behavior modifications such as smoking, exercise, and diet.

Against this background, this study aims to investigate the relationships between mental health levels, 4-year changes in lifestyle, and CVD risk factors among Japanese workers. In this study, we used the Japanese version of the SF-36, which is a comprehensive scale that measures health-related quality of life (HR-QOL) and can also describe mental health $[17,18]$. We hypothesized that workers' mental health levels would influence 4-year changes in their lifestyles and CVD risk factors.

We analyzed baseline data from the high-risk and population strategy for occupational health promotion (HIPOP-OHP) study. In brief, HIPOP-OHP was an interventional survey to establish a methodology for reducing cardiovascular disease (CVD) risk factors in the workplace. This study population consisted of full-time workers at 12 large-scale companies (mostly, manufactures of electric appliances) throughout Japan. Each company had 500 - 1000 employees. Researchers followed the data of CVD risk factors, lifestyle and consciousness about health based on nutrition, physical activity and smoking for four years. This study was performed as part of the management of safety and health with the approval of the Safety Hygiene Committee at each company. Accordingly, all employees were enrolled in this study. However, participation was voluntary, and we explained there was no need for participants to answer the required questionnaire if they did not want to. During 1999-2000, baseline data were collected from 7346 male and female workers aged from 19 to 69 years old.

\section{METHODS}

\subsection{Study Population}

In this study, the data from the "High-risk and Population Strategy for Occupational Health Promotion" (HIPOP-OHP) study were used. This was a 4-year intervention study of a large number of workers in different oc- cupational fields. Our study subjects were 4238 workers (3331 males and 905 females) who had regular medical examinations conducted by their employers and answered questionnaires both at baseline (1999 or 2000) and 4 years later (2003 or 2004).

Detailed information on the HIPOP-OHP study has been provided in several other studies [19-21]. Briefly, the HIPOP-OHP study was conducted using both population- and high-risk strategies to establish preventive measures to improve CVD risk factors. It was a 4-year intervention study conducted among subjects from 12 workplaces throughout Japan. Among the 12 workplaces, 6 sites (Companies A-F) were allocated to the intervenetion group, and the other 6 (Companies G-L) were allocated to the control group. In the intervention group, individual lifestyle modifications were performed as a high-risk strategy for subjects with positive findings of hypertension, hypercholesterolemia, diabetes, or smoking. Concurrently, environmental improvements were performed on the basis of population strategies (such as improvements to company cafeterias, promotional campaigns to increase physical activity, and inspection of designated smoking areas). In the control group, only teaching materials regarding individual lifestyle modifications were provided. The sites in the intervention group include the headquarters of a life insurance company (Company A) located in Tokyo (eastern Japan) and factories of electrical product manufacturers (Companies $\mathrm{B}, \mathrm{C}, \mathrm{E}$, and F). Company $\mathrm{C}$ is located in eastern Japan (the Kanto region), and the remaining 3 are located in western Japan (the Kinki and Hokuriku regions). Company $\mathrm{D}$ is a factory of a chemical company located in western Japan. The sites in the control group include a factory of a chemical company located in Tokyo (Company $\mathrm{H}$ ) and four electrical product manufacturers (Companies G, K, I, and J). Companies G and $\mathrm{K}$ are located in eastern Japan (the Kanto region), and Companies I and $\mathrm{J}$ are located in western Japan (the Kinki and Hokuriku regions). Company $\mathrm{L}$ is a laboratory of an electrical product manufacturer in Osaka (western Japan). Company A merged with another company in 2002, and the study could not be conducted in 2004. Therefore, in our study, the data from the remaining 11 companies were analyzed.

\subsection{Data Collection and Standardization}

Data were collected at each company in a standardized way [20]. Height and weight were measured during the regular medical examinations, and Body Mass Index (BMI) was calculated using the formula, "BMI $=$ weight $(\mathrm{kg}) /(\text { height }[\mathrm{m}])^{2}$." After the subject remained quiet in a sitting posture for 5 minutes, blood pressure was measured twice, using the same automated sphygmomanome- 
ter (BP-103ill, manufactured by Japan Colin Corporation) at all companies except Company L (TM-2654 and TM-2656, manufactured by A \& D Com Ltd.); the average value of the 2 readings was used. Total cholesterol was measured in general laboratories after international standardization of the measurement methodology by Osaka Medical Center for Health Science and Promotion, which belonged to the US Cholesterol Reference Method Laboratory Network (CRMLN) (controlled by US Centers for Disease Control and Prevention [CDC]) [22]. Information on awareness regarding diet, exercise, and smoking was collected using a self-administered questionnaire that was filled out by each subject at the time of regular medical examinations.

Information on mental health levels was collected using the "Mental Health" section of the SF-36 Health Survey (SF-36-MH), which serves as an index of HRQOL and was filled out by the subjects at baseline. HRQOL is used for medical evaluation of a concept defined as QOL limited to the measurement of aspects of individual health. SF-36 was first developed in the United States. It has been translated into more than 50 different languages and is widely used worldwide. In the preparation of each language version of the SF-36, sufficient consideration was applied to topics ranging from the construction of the concepts to psychometric assay [17,18,23-26]. SF-36-MH was used as the index of health-related QOL in the HIPOP-OHP study as well. [23-26].

Participants whose mental health levels had been measured using SF-36-MH at baseline were subject to a 4-year follow-up investigation. A longitudinal analysis of the relationships between baseline mental health levels, lifestyle changes, and cardiovascular risk factors was performed.

Mental health levels at baseline were measured by scoring the answers to the following 5 items of SF-36$\mathrm{MH}$, and total scores were then obtained for each subject:

1) Have you been very nervous?

2) Have you been very depressed and felt nothing could cheer you up?

3) Have you felt calm and peaceful?

4) Have you felt downhearted and blue?

5) Have you been happy?

The subjects were divided into 2 groups on the basis of their total scores, with the median (65) serving as a boundary between groups. The subjects with total scores of 65 or higher were allocated to the "Good Mental Health Group," and those with total scores of less than 65 were allocated to the "Poor Mental Health Group."

Awareness of nutrition was evaluated on the basis of the answer to a yes-or-no question, "Do you think there is any relationship between diet and health for you?" in the self-administered questionnaire. The subjects were divided into 2 groups depending on their answers. Behavior modification in terms of diet was evaluated on the basis of the answer to a yes-or-no question, "Have you become more careful about diet for the sake of your health in the past 1 year?" The subjects were divided into 2 groups depending on their answers. Awareness and behavior regarding diet were analyzed by comparing the results obtained at baseline with those obtained 4 years later.

In terms of smoking, the subjects were divided into the "Non-smoker" (never-smokers and ex-smokers), and "Smoker" (current smokers) Groups. Subjects' exercise states were evaluated on the basis of their answers to a yes-no question, "Are you exercising in your daily life as much as possible?" subjects were divided into 2 groups according to their answers. These aspects were analyzed by comparing the results obtained at baseline with those obtained 4 years later.

The definitions of CVD risk factors are shown in Table 1. To define obesity, we followed the BMI criteria established by Yusuf et al. [27]. The levels of normal and abnormal blood pressure were defined using the WHO guideline [28]. The criteria for normal and abnormal values of HDL and T-Cho were adopted from the definitions established by the National Cholesterol Education Program Expert Panel [29].

Approval for the study was obtained from the Institutional Review Board of Shiga University of Medical Science for ethical issues (No. 10-16).

\subsection{Statistical Analysis}

The SAS version 9.13 software package (SAS Institute, Inc.) was used for statistical analysis.

1) Sex; age; presence or absence of individuals living together; regularity of bedtime; indication of the risk of myocardial infarction, angina pectoris, cerebral stroke, hypertension, hypercholesterolemia, or diabetes; presence of intervention; relationship between one's health and diet; smoking habit; exercise; BMI; blood pressure; and total cholesterol level were compared between the good mental health and poor mental health groups at baseline using a chi-square test.

2) The odds ratios for the changes in lifestyle behavior modification in the good mental health group were calculated and compared with those in the poor mental health group. In addition, multiple logistic regression analysis was performed using lifestyle modification or change in the test values as dependent variables and mental health level, age, presence or absence of individuals living together, regularity of bedtime, and presence of intervention (the intervention group vs. the control group) as independent variables. In the analysis of 
Table 1. Baseline characteristics of the groups with good and poor mental health HIPOP-OHP study.

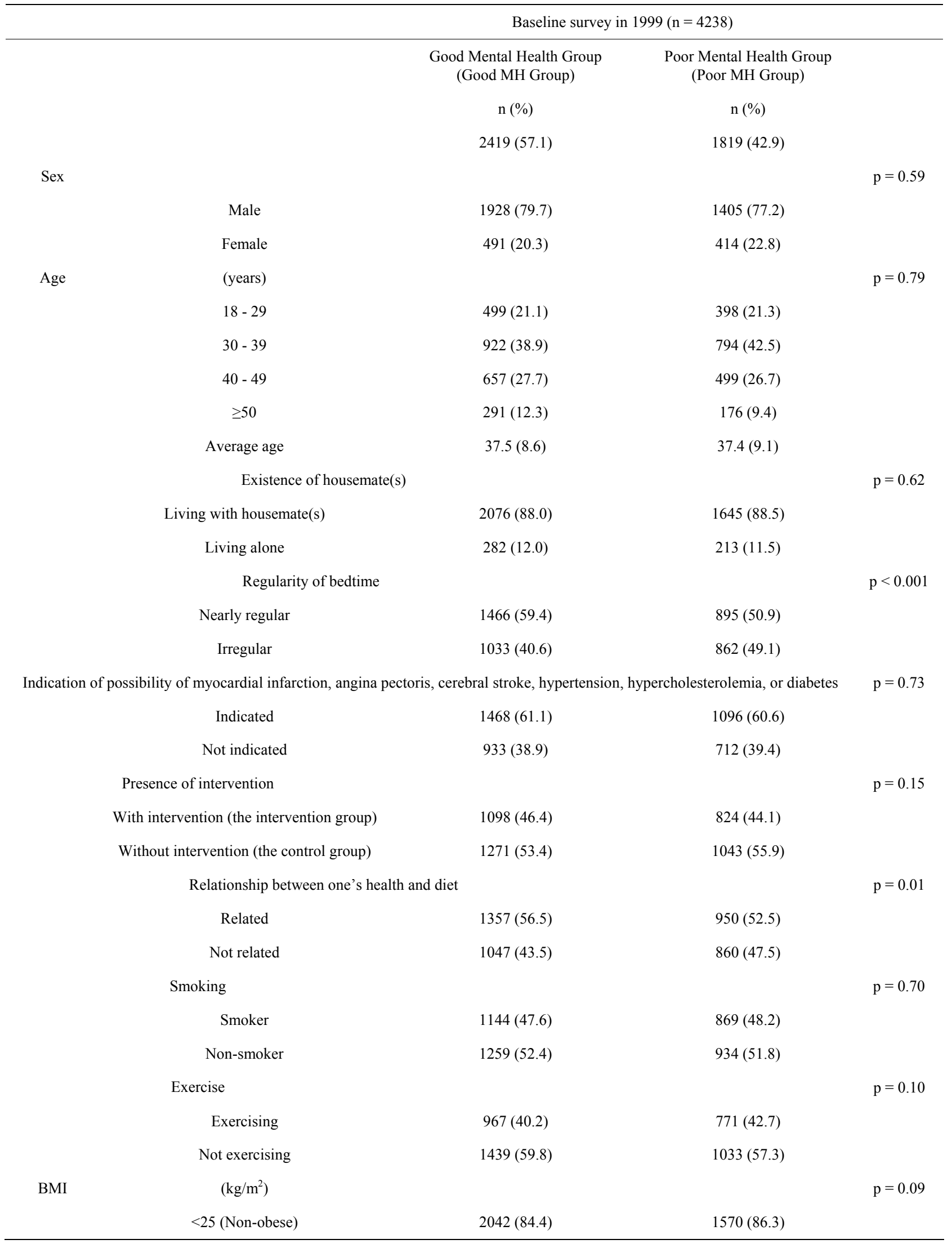




$$
\geq 25 \text { (Obese) }
$$

Blood pressure

$$
\text { Normal }^{*}
$$

Abnormal

Total cholesterol

$$
\begin{aligned}
& \text { Normal }^{* *} \\
& \text { Abnormal }
\end{aligned}
$$

HDL cholesterol

$$
377 \text { (15.6) }
$$

$2062(85.2)$

$$
357 \text { (14.8) }
$$

2238 (92.5)

$181(7.5)$

$1459(60.3)$

$960(39.7)$
249 (13.7)

$$
\mathrm{p}=0.07
$$

$1586(87.2)$

233 (12.8)

$\mathrm{p}=0.21$

1701 (93.5)

$118(6.5)$

$\mathrm{p}=0.14$

"Systolic blood pressure $<140 \mathrm{mmHg}$ and diastolic blood pressure $<90 \mathrm{mmHg} ;{ }^{* *}$ Total cholesterol $<240 \mathrm{mg} / \mathrm{dL} ;{ }^{* * *} \mathrm{HDL}$ cholesterol $\geq 40 \mathrm{mg} / \mathrm{dL}$.

lifestyle modification, indication of the risk of myocardial infarction, angina pectoris, cerebral stroke, hypertension, hypercholesterolemia, or diabetes was also included as an independent variable.

3) The odds ratios for changes in CVD risk factors in the good mental health group were calculated and compared with those in the poor mental health group. In addition, multiple logistic regression analysis was performed using lifestyle modification or change in the test values as dependent variables and mental health level, age, presence or absence of individuals living together, regularity of bedtime, and presence of intervention (the intervention group vs. the control group) as independent variables.

\section{RESULTS}

The characteristics of each group (categorized by mental health levels at baseline) are summarized in Table 1. The Good Mental Health Group consisted of 2419 subjects (57.1\%), and the Poor Mental Health Group consisted of $1819(42.9 \%)$ subjects at baseline. Male subjects accounted for approximately $80 \%$ of both groups. Subjects in their 30 s were the most common in terms of age, and about $90 \%$ of subjects in both groups were living with someone else. The bedtimes of approximately $60 \%$ of subjects were "nearly regular." About $40 \%$ of subjects indicated the possibility of having at least one of the following diseases prior to baseline measurements: myocardial infarction, angina pectoris, cerebral stroke, hypertension, hypercholesterolemia, or diabetes. Furthermore, no significant difference was observed between the 2 groups in terms of presence of intervention, smoking, exercise, BMI, blood pressure, or cholesterol at baseline.

The results of the analysis of 4-year changes in behavior modification in terms of diet and exercise, awareness about nutrition, and smoking are shown in Table 2. Multiple logistic regression analysis was performed after adjusting for age, sex, existence of housemate(s), regularity of bedtime, indication of possibility of myocardial infarction, angina pectoris, cerebral stroke, hypertension, hypercholesterolemia, diabetes, and presence of intervention at baseline; then, the ratios of subjects who were regarded as "improved" or "maintained" was compared between the Good- and Poor Mental Health Groups. The odds ratios were 1.14 (95\% CI: 1.01 1.30) for behavior modification in terms of exercise, 1.08 (95\% CI: 0.88 - 1.31) for behavior modification in terms of diet, 1.16 (95\% CI: 1.02 - 1.32) for awareness about nutrition, and 1.09 (95\% CI: 0.90 - 1.32) for behavior modification in terms of smoking.

The relationships between changes in CVD risk factors and mental health levels at baseline are shown in Table 3. Multiple logistic regression analysis was performed, and odds ratios were calculated in the same manner as above. The odds ratios were 1.20 (95\% CI: 1.03 - 1.39) for BMI, 1.20 (95\% CI: 1.01 - 1.43) for blood pressure, 1.07 (95\% CI: 0.86 - 1.33) for total cholesterol, and 1.26 (95\% CI: 1.07 - 1.47) for HDL cholesterol.

\section{DISCUSSION}

The results of our study indicated that Japanese workers with good mental health tended to improve their conditions or maintained good conditions in terms of lifestyle and CVD risk factors. On the other hand, those with poor mental health tended to have difficulty in improving their lifestyles and had high risks of CVD.

Existing mental healthcare mainly focuses on early detection and treatment of mental disorders and providing support for patients to return to work. In recent years, stress factors have been found to be closely related to 
Table 2. Four-year changes in awareness and behavior modification in the groups with good and poor mental health HIPOP-OHP study.

\begin{tabular}{|c|c|c|c|c|}
\hline & $\mathrm{n}$ & $\begin{array}{l}\text { Improved/maintained } \\
(\%)^{*}\end{array}$ & $\begin{array}{l}\text { Not-improved/worsened } \\
(\%)^{* *}\end{array}$ & $\begin{array}{l}\text { Multivariate }{ }^{* * *} \text { Odds ratio } \\
\text { (95\% confidence interval) }\end{array}$ \\
\hline \multirow[t]{3}{*}{$\begin{array}{l}\text { Behavior modification in terms of } \\
\text { exercise }\end{array}$} & 4170 & & & \\
\hline & $\begin{array}{l}\text { Poor Mental Health } \\
\text { Group }\end{array}$ & 1034 (57.9) & $751(42.1)$ & 1.00 \\
\hline & $\begin{array}{l}\text { Good Mental Health } \\
\text { Group }\end{array}$ & $1433(60.1)$ & $952(39.9)$ & $1.14(1.01-1.30)$ \\
\hline \multirow[t]{3}{*}{$\begin{array}{l}\text { Behavior modification in terms of } \\
\text { diet }\end{array}$} & 3980 & & & \\
\hline & $\begin{array}{l}\text { Poor Mental Health } \\
\text { Group }\end{array}$ & $448(26.4)$ & 1247 (73.6) & 1.00 \\
\hline & $\begin{array}{l}\text { Good Mental Health } \\
\text { Group }\end{array}$ & $594(26.0)$ & $1691(74.0)$ & $1.08(0.88-1.31)$ \\
\hline \multirow[t]{3}{*}{$\begin{array}{l}\text { Awareness about the relationship } \\
\text { between health and diet }\end{array}$} & 4171 & & & \\
\hline & $\begin{array}{l}\text { Poor Mental Health } \\
\text { Group }\end{array}$ & 973 (54.4) & 814 (45.6) & 1.00 \\
\hline & $\begin{array}{l}\text { Good Mental Health } \\
\text { Group }\end{array}$ & $1361(57.1)$ & $1023(42.9)$ & $1.16(1.02-1.32)$ \\
\hline \multirow[t]{3}{*}{ Smoking } & 3993 & & & \\
\hline & $\begin{array}{l}\text { Poor Mental Health } \\
\text { Group }\end{array}$ & $948(55.3)$ & $765(44.7)$ & 1.00 \\
\hline & $\begin{array}{l}\text { Good Mental Health } \\
\text { Group }\end{array}$ & $1268(55.6)$ & $1021(44.4)$ & $1.09(0.90-1.32)$ \\
\hline
\end{tabular}

*Exercise modification: subjects who had been consciously exercising for 4 years since baseline or who started to consciously exercise during those 4 years. Diet modification: subjects who had been careful about their diets for 4 years since baseline or who became careful during those 4 years. Health and diet: subjects who had been aware of the relationship between health and diet for 4 years since baseline or who became aware of the relationship during those 4 years. Smoking: The subjects who had been non-smokers for 4 years since baseline or who quit smoking during those 4 years; ${ }^{* *}$ Exercise modification: subjects who had not been consciously exercising for 4 years since baseline or who stopped consciously exercising during those 4 years. Diet modification: subjects who had not been careful about their diet for 4 years since baseline or who ceased being careful about their diet during those 4 years. Health and diet: subjects who had not been aware of the relationship between health and diet for 4 years since baseline or who ceased to be aware of this relationship during those 4 years. Smoking: subjects who had been smokers for 4 years since baseline or who started smoking during those 4 years; ${ }^{* * *}$ Adjusted according to the factors of Age, Existence of housemate(s), Presence of intervention, Regularity of bedtime, and Indication of possibility of myocardial infarction, angina pectoris, cerebral stroke, hypertension, hypercholesterolemia, or diabetes at baseline

increasing incidence of psychosomatic disorders. Stress management, therefore, is becoming important for the prevention of lifestyle-related diseases and as a measure taken against mental disorders [30-33]. However, there is a strong relationship between mental health and physical health, and it is not practical to take measures without integration of this idea. It has been reported in Japan that subjective stress and the state of depression are related to the pathogenesis of CVD [34,35]. Iso et al. report that the mortality rate from stroke and coronary artery diseases tends to be higher in women who have severe subjective stress [36]. However, this report is based on questionnaires and not actual medical measurements of CVD risk factors. The relationship between mental health and CVD risk factors has rarely been investigated by longitudinal research methods, and therefore, our study can be considered to provide valuable scientific evidence of the relationship between stress and CVD.

This study used SF-36-MH as an index to evaluate mental health levels. It consists of a total of 5 questions and can be answered by a subject without taking much time and energy. In Japanese workplaces, questionnaires are used to evaluate mental health levels in various situations, and the scale for depression is often employed. On the other hand, SF-36-MH can quantitatively evaluate mental health as well as depression. Such quantitative evaluation is easy for subjects to understand and is advantageous as a tool for measuring mental health at regular medical examinations.

Workers' mental health at workplaces was thought to be influenced by complicated factors and also to deteriorate thorough diverse processes. Our results clarified that subjects with deteriorated mental health were also those with a high risk of lifestyle-related diseases (e.g., obesity, 
Table 3. Four-year changes in cardiovascular risk factors in the groups with good and poor mental health-HIPOP-OHP study.

\begin{tabular}{cccc}
\hline \multicolumn{1}{c}{$n$} & Improved/maintained (\%) & Not-improved/worsened group (\%) & $\begin{array}{c}\text { Multivariate } \\
\text { Odds ratio } \\
\text { (95\% confidence interval) }\end{array}$ \\
\hline BMI & & & \\
Poor Mental Health Group & $1446(76.1)$ & $455(23.9)$ & 1.00 \\
Good Mental Health Group & $1847(79.0)$ & $490(21.0)$ & $1.20(1.03-1.39)$ \\
Blood pressure & & & 1.00 \\
Poor Mental Health Group & $1562(82.2)$ & $339(17.8)$ & $1.20(1.01-1.43)$ \\
Good Mental Health Group & $1977(84.6)$ & $360(15.4)$ & 1.00 \\
Total cholesterol & & $232(9.9)$ & $1.07(0.86-1.33)$ \\
Poor Mental Health Group & $2105(90.1)$ & $187(9.8)$ & 1.00 \\
Good Mental Health Group & $1714(90.2)$ & & $1.26(1.07-1.47)$ \\
HDL cholesterol & & $629(26.9)$ & $507(26.7)$ \\
Poor Mental Health Group & $1708(73.1)$ & $1394(73.3)$ &
\end{tabular}

*Adjusted according to the factors of age, existence of housemate(s), presence of intervention, and regularity of bedtime at baseline.

hypertension, and dyslipidemia) and indicated that consideration of mental health was necessary for the prevention of lifestyle-related diseases. Concretely, the risks of lifestyle-related diseases need to be evaluated at regular health checkups by measuring both disease factors and mental health levels using scales such as the SF-36. In addition, in order to support subjects in changing lifestyles, it might be necessary to provide health support combined with mental healthcare.

This study had several limitations. Firstly, the mental health levels measured at baseline might not necessarily remain the same for 4 years. However, from the viewpoint of the effectiveness of a screening survey, our study evaluated the predictive capability of mental health levels and might be of great significance. Secondly, mental health levels were categorized as "Good" or "Poor" on the basis of the median of the study subject group. However, the appropriate values to discriminate good vs. poor mental health levels need to be investigated further in studies with larger populations.

\section{CONCLUSION}

This study showed that lifestyle and CVD risk factors could be maintained in satisfactory condition or improved when mental health was better. To prevent lifestyle-related diseases, the risk factors for them need to be evaluated with attention to mental health. In addition, to provide support for lifestyle change, it might be necessary to provide health support combined with mental healthcare.

\section{ACKNOWLEDGEMENTS}

This study was funded by research grants from the Ministry of Health and Welfare, Japan (H10-12, No. 063, Research on Health Services, Health Sciences Research Grants, H13, No. 010, Medical Frontier Strategy Research, Health Sciences Research Grants), the Ministry of Health, Labor and Welfare, Japan (H14-15, No. 010, Clinical Research for Evidenced-Based Medicine, Health and Labor Sciences Research Grants), and the Japan Arteriosclerosis Prevention Fund (2000 and 2004). We thank Toshimi Yoshida of the Department of Health Science at Shiga University of Medical Science for her excellent clerical support in this research.

\section{REFERENCES}

[1] Statistics and Information Department, Minister's Secretariat, Ministry of Health and Welfare (1990) Vital Statistics, 1965-1990, Japan.

[2] Ueshima, H. (1990) Changes in dietary habits, cardiovascular risk factors and mortality in Japan. Acta Cardiologica, 45, 311-327.

[3] Bijnen, F.C., Caspersen, C.J., and Mosterd, W.L. (1994) Physical inactivity as a risk factor for coronary heart disease: A WHO and international society and federation of cardiology position statement. Bulletin of the World Health Organization, 72, 1-4.

[4] Trichopoulou, A., Costacou, T., Bamia, C. and Trichopoulos, D. (2003) Adherence to a Mediterranean diet and survival in a Greek population. The New England Journal of Medicine, 348, 2599-2608. doi:10.1056/NEJMoa025039

[5] Haveman-Nies, A., De Groot, L.P.G.M., Burema, J., Cruz, 
J.A.A., Osler, M. and Van Staveren, W.A. (2002) Dietary quality and lifestyle factors in relation to 10 -year mortality in older Europeans: The SENECA study. American Journal of Epidemiology, 156, 962-968. doi:10.1093/aje/kwf144

[6] Huijbregts, P.P., Feskens, E.J., Räsänen, L., Fidanza, F., Alberti-Fidanza, A., Nissinen, A., Giampaoli, S. and Kromhout, D. (1998) Dietary patterns and cognitive function in elderly men in Finland, Italy and The Netherlands. European Journal of Clinical Nutrition, 52, 826-831. doi:10.1038/sj.ejen.1600654

[7] Kadota, A., Hozawa, A., Okamura, T., Kadowak, T., Nakmaura, K., Murakami, Y., Hayakawa, T., Kita, Y., Okayama, A., Nakamura, Y., Kashiwagi, A. and Ueshima, H. (2007) Relationship between metabolic risk factor clustering and cardiovascular mortality stratified by high blood glucose and obesity: NIPPON DATA90, 1990-2000. Diabetes Care, 30, 1533-1538. doi:10.2337/dc06-2074

[8] Nakamura, Y., Iso, H., Kita, Y., Ueshima, H., Okada, K., Konishi, M., Inoue, M. and Tsugane, S. (2006) Egg consumption, serum total cholesterol concentrations and coronary heart disease incidence: Japan Public Health Center-based prospective study. The British Journal of Nutrition, 96, 921-928. doi:10.1017/BJN20061937

[9] Kawakami, N. and Haratani, T. (1999) Epidemiology of job stress and health in Japan: Review of current evidence and future direction. Industrial Health, 37, 174-186. doi:10.2486/indhealth.37.174

[10] Aboa-Eboulé, C., Brisson, C., Maunsell, E., Mâsse, B., Bourbonnais, R., Vézina, M., Milot, A., Théroux, P. and Dagenais, G.R. (2007) Job strain and risk of acute recurrent coronary heart disease events. The Journal of the American Medical Association, 298, 1652-1660. doi:10.1001/jama.298.14.1652

[11] Johnson, J., Hall, E.M. and Theorell, T. (1989) Combined effects of job strain and social isolation on cardiovascular disease morbidity and mortality in a random sample of the Swedish male working population. Scandinavian Journal of Work, Environment, and Health, 15, 271-279. doi:10.5271/sjweh.1852

[12] Sokejima, S. and Kagamimori, S. (1998) Working hours as a risk factor for acute myocardial infarction in Japan: Case-control study. British Medical Journal, 317, 775780. doi:10.1136/bmj.317.7161.775

[13] Kawakami, N., Tsutsumi, A., Haratani, T., Kobayashi, F., Ishizaki, M., Hayashi, T., Fujita, O., Aizawa, Y., Miyazaki, S., Hiro, H., Masumoto, T., Hashimoto, S. and Araki, S. (2006) Job strain, worksite support, and nutrient intake among employed Japanese men and women. Journal of Epidemiology, 16, 79-89. doi:10.2188/jea.16.79

[14] Kondo, K., Kobayashi, Y., Hirokawa, K., Tsutsumi, A., Kobayashi, F., Haratani, T., Araki, S. and Kawakami, N. (2006) Job strain and sick leave among Japanese employees: A longitudinal study. International Archives of Occupational and Environmental Health, 79, 213-219. doi:10.1007/s00420-005-0027-x

[15] Ruberman, W., Weinblatt, E., Goldberg, J.D. and Chaudhary, B.S. (1984) Psychosocial influences on mortality after myocardial infarction. The New England Journal of Medicine, 311, 552-559.

\section{doi:10.1056/NEJM198408303110902}

[16] Janzon, L., Hanson, B.S., Isacsson, S.O., Lindell, S.E. and Steen, B. (1986) Factors influencing participation in health surveys: Results from prospective population study "men born in 1914" in Malmo, Sweden. Journal of Epidemiology and Community Health, 40, 174-177. doi:10.1136/jech.40.2.174

[17] Fukuhara, S., Bito, S., Green, J., Hsiao, A. and Kurokawa, K. (1998) Psychometric and clinical tests of validity of the Japanese SF-36 Health Survey. Journal of Clinical Epidemiology, 51, 1045-1053. doi:10.1016/S0895-4356(98)00096-1

[18] Fukuhara, S., Bito, S., Green, J., Hsiao, A. and Kurokawa, K. (1998) Translation, adaptation, and validation of the SF-36 Health Survey for use in Japan. Journal of Clinical Epidemiology, 51, 1037-1044. doi:10.1016/S0895-4356(98)00095-X

[19] Naito, M., Nakayama, T., Okamura, T., Miura, K., Yanagita, M., Fujieda, Y., Kinoshita, F., Naito, Y., Nakagawa, H., Tanaka, T. and Ueshima, H. (2007) Effect of a 4-year workplace-based physical activity intervention program on the blood lipid profiles of participating employees: The high-risk and population strategy for occupational health promotion (HIPOP-OHP) study. Atherosclerosis, 197, 784-790.

[20] Okamura, T., Tanaka, T., Babazono, A., Yoshita, K., Chiba, N., Takebayashi, T., Nakagawa, H., Yamato, H., Miura, K., Tamaki, J., Kadowaki, T., Okayama, A. and Ueshima, H. (2004) The high-risk and population strategy for occupational health promotion (HIPOP-OHP) study: Study design and cardiovascular risk factors at the baseline survey. Journal of Human Hypertension, 18, 475-485. doi:10.1038/sj.jhh.1001680

[21] Tanaka, H., Yamato, H., Tanaka, T., Kadowaki, T., Okamura, T., Nakamura, M., Okayama, A. and Ueshima, H. (2006) Effectiveness of a low-intensity intra-worksite intervention on smoking cessation in Japanese employees: A three-year intervention trial. Journal of Occupational Health, 48, 175-182. doi:10.1539/joh.48.175

[22] Nakamura, M., Sato, S. and Shimamoto, T. (2003) Improvement in Japanese clinical laboratory measurements of total cholesterol and HDL-cholesterol by the US Cholesterol Reference Method Laboratory Network. Journal of Atherosclerosis and Thrombosis, 10, 145-153. doi: $10.5551 /$ jat.10.145

[23] Yamazaki, S., Fukuhara, S., Suzukamo, Y., Morita, S., Okamura, T., Tanaka, T. and Ueshima, H. (2007) Lifestyle and work predictors of fatigue in Japanese manufacturing workers. Occupational Medicine, 57, 262-269. doi:10.1093/occmed/kqm006

[24] Saito, I., Okamura, T., Fukuhara, S., Tanaka, T., Suzukamo, Y., Okayama, A. and Ueshima, H. (2005) A crosssectional study of alcohol drinking and health-related quality of life among male workers in Japan. Journal of Occupational Health, 47, 496-503. doi:10.1539/joh.47.496

[25] Hayashino, Y., Fukuhara, S., Suzukamo, Y., Okamura, T., Tanaka, T. and Ueshima, H. (2007) Relation between sleep quality and quantity, quality of life, and risk of developing diabetes in healthy workers in Japan: The 
high-risk and population strategy for occupational health promotion (HIPOP-OHP) study. BMC Public Health, 7, 129. doi:10.1186/1471-2458-7-129

[26] Hayashino, Y., Fukuhara, S., Suzukamo, Y., Okamura, T., Tanaka, T. and Ueshima, H. (2007) Normal fasting plasma glucose levels and type 2 diabetes: The high-risk and population strategy for occupational health promotion (HIPOP-CHP) study. Acta Diabetologia, 44, 164-166. doi:10.1007/s00592-007-0258-2

[27] Yusuf, S., Hawken, S., Ounpuu, S., Bautista, L., Franzosi, M.G., Commerford, P., Lang, C.C., Rumboldt, Z., Onen, C.L., Lisheng, L., Tanomsup, S., Wangai, P., Razak, F., Sharma, A.M. and Anand, S.S. (2005) Obesity and the risk of myocardial infarction in 27000 participants from 52 countries: A case-control study. Lancet, 366, 16401649. doi:10.1016/S0140-6736(05)67663-5

[28] Guidelines Subcommittee (1999) World Health Organization-International Society of Hypertension. Guidelines for the Management of Hypertension. Journal of Hypertension, 17, 151-183.

[29] National Cholesterol Education Program Expert Panel (2001) Executive summary of the third report of the National Cholesterol Education Program (NCEP) Expert Panel on Detection, Evaluation, and Treatment of High Blood Cholesterol in Adults (Adult Treatment Panel III). Journal of the American Medical Association, 285, 24862497. doi:10.1001/jama.285.19.2486

[30] Spurgeon, A., Harrington, J.M. and Cooper, C.L. (1997) Health and safety problems associated with long working hours: A review of the current position. Occupational and Environmental Medicine, 54, 367-375. doi:10.1136/oem.54.6.367

[31] Parkes, C.M., Benjamin, B. and Fitzgerald, R.G. (1969) Broken heart: A statistical study of increased mortality among widowers. British Medical Journal, 1, 740-743. doi:10.1136/bmj.1.5646.740

[32] Ohira, T., Iso, H., Satoh, S., Sankai, T., Tanigawa, T., Ogawa, Y., Imano, H., Sato, S., Kitamura, A. and Shimamotom, T. (2001) Prospective study of depressive symptoms and risk of stroke among Japanese. Stroke, 32, 903908. doi:10.1161/01.STR.32.4.903

[33] Iso, H, Date, C., Yamamoto, A., Toyoshima, H., Tanabe, N., Kikuchi, S., Kondo, T., Watanabe, Y., Wada, Y., Ishibashi, T., Suzuki, H., Koizumi, A., Inaba, Y., Tamakoshi, A. and Ohno, Y. (2002) Perceived mental stress and mortality from cardiovascular disease among Japanese men and women: The Japan collaborative cohort study for evaluation of cancer risk sponsored by Monbusho (JACC study). Circulation, 106, 1229-1236. doi:10.1161/01.CIR.0000028145.58654.41

[34] Janzon, L., Hanson, B.S., Isacsson, S.O., Lindell, S.E. and Steen, B. (1986) Factors influencing participation in health surveys: Results from prospective population study "men born in 1914" in Malmo, Sweden. Journal of Epidemiology and Community Health, 40, 174-177. doi:10.1136/jech.40.2.174

[35] Ohira, T., Iso, H., Satoh, S., Sankai, T., Tanigawa, T., Ogawa, Y., Imano, H., Sato, S., Kitamura, A. and Shimamotom, T. (2001) Prospective study of depressive symptoms and risk of stroke among Japanese. Stroke, 32, 903908. doi:10.1161/01.STR.32.4.903

[36] Iso, H., Date, C., Yamamoto, A., Toyoshima, H., Tanabe, N., Kikuchi, S., Kondo, T., Watanabe, Y., Wada, Y., Ishibashi, T., Suzuki, H., Koizumi, A., Inaba, Y., Tamakoshi, A. and Ohno, Y. (2002) Perceived mental stress and mortality from cardiovascular disease among Japanese men and women: The Japan collaborative cohort study for evaluation of cancer risk sponsored by Monbusho (JACC study). Circulation, 106, 1229-1236. doi:10.1161/01.CIR.0000028145.58654.41 